\title{
THE METHODS SECTIONS IN MANAGEMENT AND MARKETING RESEARCH ARTICLES: RHETORICAL VARIATIONS BETWEEN TWO SUB-DISCIPLINES OF BUSINESS
}

\author{
Issra Pramoolsook ${ }^{1^{*}}$, Qian $\mathrm{Li}^{2}$, Sheng Wang ${ }^{3}$ \\ ${ }^{1}$ Assistant Professor, School of Foreign Languages, Suranaree University of Technology, \\ THAILAND, issra@sut.ac.th \\ ${ }^{23} \mathrm{PhD}$ Student, School of Foreign Languages, Suranaree University of Technology, THAILAND \\ qian2007816@gmail.com, hero845@126.com \\ ${ }^{*}$ Corresponding author
}

\begin{abstract}
Recently, studies on rhetorical structure of research articles (RAs) have attracted a great attention of researchers. Among the sections of RA, the Introduction section has been investigated extensively while much fewer studies have been done on the Methods section. Besides, the majority of the existing studies focus only on a single discipline or on a comparison between two disciplines. Very little, however, has been conducted to compare the rhetorical structure between two sub-disciplines from one academic field. In this study, therefore, the Methods sections from Management and Marketing, two sub-disciplines of business, were analyzed and compared to identify the rhetorical variations due to disciplinary concepts and practices between these two sub-disciplines. Two sets of corpus were compiled, each with ten Methods sections from two prestigious journals in the fields of Management and Marketing, respectively. Lim's model (2006) for the rhetorical structure of the Methods section in Management was adopted as the analytical framework. Results of the analysis showed that the chosen analytical framework could not offer sufficient explanations for the rhetorical structure of the Methods sections in the two sub-disciplines of business, even revealing some discrepancies between the framework and the actual texts. Only 30\% of the Methods sections in the Management corpus appeared to fit the selected model while in the Marketing corpus, the Methods sections had a greater diversity of rhetorical patterns due to the requirements for publishing in the two selected Marketing journals. The findings in this study may have some implications for writing the Methods sections in the business discipline, such as the need for explicit instruction of writing conventions of this particular section and the guidance to realize the rhetorical differences between these two sub-disciplines for more effective sub-discipline specific writing.
\end{abstract}

Keywords: The Methods Section, Research Article, Management, Marketing, Disciplinary Variations

\section{INTRODUCTION}

The increasing interest in investigation of research articles (RAs) is due to the rich recourses they can provide for examining the writing conventions. A substantial amount of studies have been done on rhetorical structures of a whole research article (e.g. Nwogu, 1997; Posteguillo, 1999; Kanoksilapatham, 2005) or individual sections in research articles, such as the Introduction (e.g. Swales, 1990; 2004; Samraj, 2002), the Methods section (e.g. Lim, 2006; Peacock, 2011), the Results section (e.g. Brett, 1994; Lim, 2010), the Discussion section (e.g. Peacock, 2002), and the Conclusion (e.g. Yang and Allison, 2003). Among these, the Introduction 
section has been studied quite extensively and been given a very important place while much fewer studies have been done on the Methods section. Inadequate attention to this section may be due to the misunderstanding of the section that writing up this section is often viewed as an easy, straightforward job. However, it is not easy if one expects to write a clear and concise one (Swales, 1990; 2004; Weissberg and Buker, 1990)

The Methods section generally describes procedures used in the study being reported (Kanoksilapatham, 2005). The communicative purposes of the Methods section are to present how data were collected, the procedure for the experiment or measuring variables, and how data analysis was conducted. The purpose of the Methods section is to inform the reader about the research methods used in the study, and also it provides evidences for reliability and validity of results reported in the Results section (Swales and Feak, 2004). Moreover, it makes it possible for those who are equipped with substantial background knowledge and are interested in this particular field to conduct future replication as well (Swales, 2004). Based on the models identified by previous studies (Nwogu, 1997; Kanoksilapatham, 2005; Lim, 2006), the Methods section is generally structured in the order of data collection, experiment/variable measurement, and data analysis.

Among the existing studies on the Methods section, Lim (2006) proposed the model for management, and Peacock (2011) suggested a structure of seven moves which possibly appear in the section based on his analysis of the Methods section from 8 disciplines. However, no research has been conducted to compare the rhetorical structure of this section between two sub-disciplines from one field. In the present study, the Methods sections from two related fields, Management and Marketing, two sub-disciplines of Business, were therefore analyzed in order to explore whether there are any differences in the move-step structure between these two related disciplines.

\section{METHODS}

\subsection{Corpora Compilation}

Two sets of corpus were compiled, categorized according to the disciplines, and coded as Ma for Management and Mk for Marketing. The Ma corpus for the present study consists of 10 research article Methods sections randomly selected from 2 prestigious journals: International Journal of Project Management (IJPM) and Journal of Operations Management (JOM) while the Mk ones are from International Journal of Research in Marketing (IJRM) and Journal of Interactive Marketing (JIM), with 5 from each journal. All these selected research articles were published in 2011 and exhibit the Introduction-Methods-Results-Discussion (IMRD) organization. These 20 RA Methods sections yield corpora of approximately 29,000 words.

\subsection{Analytical Framework}

Lim's model (2006) was adopted as the analytical framework for the present study (see Table 1) for the following reasons. First, it seems that Lim's model is a comprehensive model for analyzing Methods section of research articles. It provides a very detailed description of each move. Also, Lim (2006) arrived at this model by analyzing RAs from the field of Management, which is the same or close to the target disciplines in the present study.

Table 1: Lim's model (2006) for RA Methods sections of Management

\begin{tabular}{|c|c|}
\hline Rhetorical move & Constituent step \\
\hline $\begin{array}{l}\text { Move } 1: \text { Describing data collection } \\
\text { procedure/s }\end{array}$ & $\begin{array}{l}\text { Step 1: Describing the sample } \\
\text { (a) Describing the location of the sample } \\
\text { (b) Describing the size of the sample/population } \\
\text { (c) Describing the characteristics of the sample } \\
\text { (d) Describing the sampling technique or criterion } \\
\text { Step 2: Recounting steps in data collection } \\
\text { Step 3: Justifying the data collection procedure/s } \\
\text { (a) Highlighting advantages of using the sample } \\
\text { (b) Showing representativity of the sample }\end{array}$ \\
\hline $\begin{array}{l}\text { Move 2: Delineating procedure/s for } \\
\text { measuring variables }\end{array}$ & $\begin{array}{l}\text { Step 1: Presenting an overview of the design } \\
\text { Step 2: Explaining method/s of measuring variables } \\
\text { (a) Specifying items in questionnaires/databases } \\
\text { (b) Defining variables } \\
\text { (c) Describing methods of measuring variables } \\
\text { Step 3: Justifying the method/s of measuring variables } \\
\text { (a) Citing previous research method/s } \\
\text { (b) Highlighting acceptability of the method/s }\end{array}$ \\
\hline $\begin{array}{l}\text { Move } 3: \text { Elucidating data analysis } \\
\text { procedure/s }\end{array}$ & $\begin{array}{l}\text { Step 1: Relating (or 'recounting') data analysis procedure/s } \\
\text { Step 2: Justifying the data analysis procedure/s } \\
\text { Step 3: Previewing results }\end{array}$ \\
\hline
\end{tabular}




\subsection{Analysis Procedure}

The present study only focused on move identification which was conducted manually. Move analysis was conducted at sentence level. "Sentence-level analysis means looking at individual sentences and to be aware that a single sentence can constitute one move" (Peacock, 2011).

Inter-rater reliability suggested by Crooks (1986) was conducted to avoid subjectivity caused by manual analysis. To ensure higher reliability, the analysis of texts was conducted by two researchers. The two raters worked independently, compared the results, discussed wherever any differences occurred and then tried to reach agreement at step level.

\section{RESULTS AND DISCUSSION}

\subsection{Move Structures}

Table 2 presents the move structures of RA Methods sections in the Management corpus, revealing that five different patterns of move structure existed in this corpus. Among them, M1-M2-M3 and M1-M3 were the predominant patterns, which occurred in $30 \%$ (3 out of 10) of RA Methods sections.

Table 2: Move structure of RA Methods sections in the Management corpus

\begin{tabular}{|l|l|l|}
\hline Management & Moves & Number of move units \\
\hline Ma 1 & M2-M1-M2-M3 & 4 \\
\hline Ma 2 & M1-M2 & 2 \\
\hline Ma 3 & M1-M2 & 2 \\
\hline Ma 4 & M2-M1-M3 & 2 \\
\hline Ma 5 & M1-M2-M3 & 3 \\
\hline Ma 6 & M1-M2-M3 & 3 \\
\hline Ma 7 & M1-M3 & 2 \\
\hline Ma 8 & M1-M3 & 1 \\
\hline Ma 9 & M1-M3 & 2 \\
\hline Ma 10 & M1-M2-M3 & 3 \\
\hline
\end{tabular}

The results suggest that only minority of RA Methods sections (30\%) in Management corpus follow Lim's model (2006), M1-M2-M3, which describes data collection procedure in Move 1, then delineates procedure for measuring variables in Move 2, and elucidates data analysis procedure in Move 3. Fifty percent researchers from the corpus tend to use only two moves, and either Move 2 or Move 3 was excluded from the selected model.

Table 3 shows that RA Methods sections in the Marketing corpus have even a greater variety of move structure patterns and more move units were included. Each RA Methods section has its own move structure pattern, only 1 out of ten fitted Lim's model (2006) (Mk 7).

Table 3: Move structure of RA Methods sections in the Marketing corpus

\begin{tabular}{|l|l|l|}
\hline Marketing & Moves & Number of move units \\
\hline Mk 1 & M2-M1-M3-M2-M1-M3 & 6 \\
\hline Mk 2 & M2-M1-M3-M2-M1-M2-M1-M2-M1-M2 & 10 \\
\hline Mk 3 & M1-M2-M1-M2-M1-M2-M3 & 7 \\
\hline$M k ~ 4$ & M1-M2-M1-M2 & 4 \\
\hline$M k$ 5 & M2-M1-M2-M3 & 4 \\
\hline$M k 6$ & $M 1-M 2-M 3-M 2-M 3$ & 5 \\
\hline
\end{tabular}


IJASOS- International E-Journal of Advances in Social Sciences, Vol. I, Issue 2, August 2015

\begin{tabular}{|l|l|l|}
\hline Mk 7 & M1-M2-M3 & 3 \\
\hline Mk 8 & M1-M3-M1-M3-M2 & 5 \\
\hline Mk 9 & M2-M1-M3-M2-M3 & 5 \\
\hline Mk 10 & M2-M1-M3-M2 & 4 \\
\hline
\end{tabular}

The results suggest that much greater varieties of move structures existed in the Marketing corpus than in the Management one. Moreover, it seems that there was no specific structure model shared by any two RA Methods sections in Marketing. The reason for such wide diversities in move structure may be explained by the editorial policies of these two journals selected for this study, which suggest that research approaches and methodologies can be diverse, and any RA with replication of research methods will be rejected. Publication acceptance in these two journals heavily depends on uniqueness, creativity and diversity, as stated in the guidelines for contributors of these journals.

\subsection{Detailed Description of RA Methods Sections in the Two Sub-disciplines}

\subsubsection{Move 1: Describing data collection procedure/s}

The Methods sections most often start by describing data collection procedure. Three steps may be employed to accomplish this move based on Lim's (2006) model. The sample may be described, steps in data collection may be recounted and data collection procedure may be justified.

Table 2 shows that almost all RA Method sections except Ma 1 and Ma 4 in the Management corpus began with Move 1, which is a universal practice according to previous studies by Nwogu (1997), Kanoksilapatham (2005), Lim (2006), while only 50\% of Methods sections in the Marketing corpus started with this move, and $50 \%$ began with Move 2. It is possible that providing some background information about the research design first is more important than describing data collection procedures at the beginning in Marketing. The reader could have a first global idea of how the study would be carried out, and they could judge whether the design of the study is reasonable or not. This could explain why half of researchers put Move 2 in the beginning of the Methods sections instead of Move 1.

According to Lim (2006), describing the sample is a step that includes statements on: 1) the location or source of the sample, 2) the size of the population, 3) the characteristics of the sample, and 4) sampling techniques or criteria. Among these four sub-steps, the size of the population may be regarded as an important element. Ninety percent of RA Methods sections in both of the sub-disciplines had this sub-step. The reason for this high occurrence rate may be due to the importance of the sample size in research. The size of the sample determines both the reliability and validity of a study. Neither Ma 10 nor Mk 5 gave the exact size of the sample, but they still provided some information about the sample (see Examples 1 and 2).

1. Target respondents of this study were members of IS development teams of recently completed projects. The unit of analysis is the IS development project team in which the participant was recently working. (Ma 10)

2. Subjects for the laboratory experiment were recruited through a mailing list at a North-American college. (Mk 5)

Generally, these four sub-steps in Move 1 occurred in a flexible order in majority of the Methods sections analyzed. If the researcher thought the way of writing was logical and clear, he/she could arrange these elements in an acceptable way, and this element arrangement did not necessarily follow the order suggested by Lim (2006) (see Example 3). In many cases, one sub-step was embedded in one of the other three substeps (see Example 4).

3. The target population is composed of Spanish firms. The list of these companies was obtained from the Sistemas de Analisis de Balances Ibericos (SABI) database. We selected firms from these database using the following criteria: the extent to which SCM is an important activity of their operations, the diversity of industrial sectors, and the size of organizations (medium- and large-sized). Small firms were excluded because in general they tend to rely on individual managers' social capital to gain access to new resources and because they tend to lack resources to invest in building social capital with supply chain partners. Service organizations (e.g., con-sultants and auditors) were excluded from our target population because they operate based on intangible resources (Chase et al., 2006). The list gave us 1014 firms. Of these, 284 firms could not be contacted due to incorrect contact information, so our final list included 730 firms. (Ma 5) 
4. A listing of 1350 plant and operations managers was extracted from the 2004 Manufacturer's News, incorporated database of U.S. manufacturers with more than 250 employees. (Ma 3)

Regarding Move 1-Step 2, all the ten Methods sections in the Management corpus recounted steps in data collection, while only seven Methods sections in Marketing field contained this step. As mentioned earlier, eighty percent of Methods sections present data collection procedure as Move 1 in Management. This may indicate that collecting data is viewed as a vital procedure in Management research. Therefore, it is natural to describe the steps in data collection in detail.

Sixty percent of the Methods sections from the Management discipline employed Move 1-Step 3, while only 3 out of 10 contained this step in Marketing. That is to say, justifying the data collection procedure was more common in Management than in Marketing. This step was accomplished either by highlighting advantages of using samples or showing the representativeness of the sample, or by both. In the analysis, it was easy to identify certain sentence/s as Move 1-Step 3, but it was difficult to categorize this step further into either sub-step proposed by Lim (2006). That is, the researcher could still justify the data collection procedure in other ways which were not suggested in Lim's model (2006). This may be the weakness of this selected model in which only these two sub-steps were included in Move 1-Step 3. (see Examples 5 and 6)

5. From this group, we made an initial selection of projects, in which we essentially employed a "most similar/most different" strategy (Yin, 2003). (Ma 9)

6. A descriptive profile of respondents was prepared, and the early and late respondents were compared to access for non-response bias. (Ma 3).

In Example 5, the writer justified the data collection procedure by citing previous data collection method. In addition to Ma 9, Ma 1 justifies the data collection procedure in this way as well. However, in Example 6, Ma 3 accomplishes the justification by describing what was exactly done with the sample, which is not accounted for in Lim's model (2006).

\subsubsection{Move 2: Delineating Procedure/s for Measuring Variables}

On the whole, Table 2 shows that Ma 7, Ma 8, and Ma 9 did not employ Move 2 at all. They jumped from Move 1 to Move 3, while Table 3 showed that all the Methods sections in the Marketing corpus contained this move, which was located at the beginning of the Methods section, or between Move 1 and Move 3, or even in the end. This may confirm the assumption made earlier that Move 2 plays an important role in the Methods sections in the Marketing field.

Move 2 explains and emphasizes how variables will be measured in the overall design of the study. According to Lim's model (2006), Move 2 starts with Step1 presenting an overall design. However, it was found that only

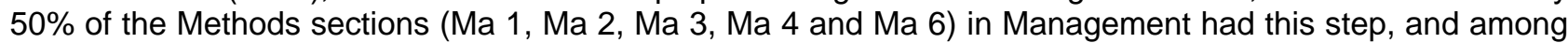
these four sections, only Ma 1 and Ma 4 provided the research design at the very beginning of the Methods sections, describing the design of questionnaires, piloting test and rationales for the design in the literature. However, $80 \%$ of the Methods sections in the Marketing corpus contained this step, and $50 \%$ of them presented the overview of the design first. From the percentages mentioned above, it seems that the Marketing papers place more emphasis on the research design, and the writers tend to provide an overview of how the research is designed, and to guide the reader to preview what would be done next.

Obviously, Table 3 showed that in Move 2- Step 2, RA Methods sections in Marketing included more sub-step ' $a$ ' and sub-step ' $c$ ' than in the Management corpus. Eighty percent of the Methods section in Marketing included sub-step ' $a$ ', which specifies items in questionnaires or databases; while only $40 \%$ of the Methods sections in Management employed sub-step ' $a$ '. In terms of occurrence percentage of sub-step ' $c$ ', all ten Marketing papers described how to measure variables, while only $60 \%$ Management papers employed this sub-step. Again, these differences confirmed the assumption that Move 2 plays an important role in Marketing papers than in Management ones.

Frequent occurrence of cyclical patterns and embedded steps/sub-steps are two very eminent features in Move 2. Generally, there were several variables in one study, and these variables need to be described how they were measured. Therefore, the researchers have to repeat the procedures for such measurements (see Example 7). This finding is very similar to the statement by Peacock (2011), who claimed that move cycles were very common in his study. The only difference lies in the different levels of analysis. In Peacock's study (2011), text analysis was conducted at move level, so the cyclical pattern was called move cycles, while the present study went further to the steps and sub-steps level. The frequency of reoccurrence of some of steps 
and sub-steps depended on the number of variables in the study. That means the more variables are included in the study, the more frequent occurrence of cycle patterns would be present.

7. We test the hypotheses using a 2 (perceived social relationship among net pals: strong vs. weak) $\times 2$ (message statements: positive vs. negative) $\times 2$ (experience vs. credence goods) between-participants factorial design. (Mk 1)

In addition to cyclical patterns, existence of embedding move was very common in both fields as well. Normally, embedment occurred among steps/sub-steps. That is to say, one step/sub-step was embedded in another and these two steps/sub-steps were within Move 2 (see Example 8). Despite the existence of embedding steps/sub-steps in Move 1 and Move 3, embedment occurred heavily in Move 2 in both fields. The typical embedment pattern was Move 2-Step 3 embedded in Move 2-Step 2. The possible reason is that after variables measurement was described, the researcher would often provide supporting evidence to justify the methods of measuring variables to increase the credibility of both the research methods and the results.

8. Following the research of Griffith et al. (2001) and feedback from the field interviews, we measured the manufacturer's knowledge acquisition (MKA) using eight items (Cronbach's a=0.932) to reflect the level of market knowledge which the manufacturer acquires from the distributor, such as knowledge about products, markets, competitors, market profiles and market shares. Following the research of Rawwas et al. (1997) and Song et al. (2006), we measured constructive conflict (CC) using four items (Cronbach's a= 0.825) to portray conflicts that bring constructive consequences and give benefit to both parties.... (Ma 1)

\subsubsection{Move 3: Elucidating Data Analysis Procedure/s}

Move 3 contains three steps which do not have sub-steps. This move explains data analysis procedure. The functions of this move are to analyze data, test the research hypotheses, and seek answers to the research questions (Lim, 2006). Not all papers from these two fields contained this move in the Methods section. Ma 2 , Ma 3 and Mk 4 did not have this Move 3. However, all these three papers incorporate data analysis procedure into the following section-the Results. It is possible that the merge of data analysis with reported results may make it easier for the researchers to present the results. In this way, the researchers do not need to refer back to data analysis procedure in the Methods sections when necessary to remind the reader of how the results occurred.

Despite the low frequent step embedment occurrence, Move 3-Step 2 embedded in Move 3- Step 1 was a common embedding pattern in Move 3. Recounting and justifying data analysis procedure appeared as a pair to create the credibility of data analysis. (See Example 9)

9. We centered all independent variables to zero prior to creating the squared size term in order to minimize potential multi-collinearity in the square terms (Aiken and West, 1991). Variance inflated factor (VIF) scores were calculated for the variables in each regression model. All VIF scores were below 4, and most were below 2, .... (Ma 5)

\section{CONCLUSION}

Results of the analysis of 20 RA Methods sections in Management and Marketing showed that the majority of the sections did not follow exactly Lim's model (2006) which is viewed as the only model for the Methods sections in Management. Only 30\% of the Methods sections in the Management corpus appeared to fit the selected model. Fifty percent of the sections lacked one move and had only two moves, while in the Marketing corpus, the Methods sections had greater diversity of move patterns due to the requirements for publishing in the two selected Marketing journals. The location and occurrence frequency in Move 2 in Marketing papers indicate the importance of the variable measurement in Marketing research. Step embedment and cycle pattern were two very common incidences in the Methods sections from both the disciplines. Also, the steps and sub-steps in all the three moves do not necessarily follow the sequence suggested by Lim (2006).

Two limitations of this study are obvious. One weakness is the small size of corpus with only 20 Methods sections from limited number of journals. Therefore, the findings of the present study may not be generalized. The other limitation results from the fact that the researchers were unable to interview the writers of the Methods sections in the corpus to confirm the findings.

Nevertheless, the findings in this study may have some implications for writing up the Methods sections in business discipline. The teacher should provide explicit instruction of writing conventions in this particular 
genre. Students need to be given guidance to realize that differences occur even between these two subdisciplines.

\section{REFERENCE LIST}

Basturkmen, H. (2012). "A Genre-Based Investigation of Discussion Sections of Research Articles in Dentistry and Disciplinary Variation". Journal of English for Academic Purposes, 11.

Brett, P. (1994). "A Genre Analysis of the Result Section of Sociology Articles: A Corpus Study". English for Specific Purposes, 13(1).

Crookes, G. (1986). "Towards A Validated Analysis of Scientific Text Structure”. Applied Linguistics, 7 (1).

Kanoksilapatham, B. (2005). "Rhetorical Structure of Biochemistry Research Articles". English for Specific Purposes, 24 (3).

Lim, J. M. H. (2006). "Method Sections of Management Research Articles: A Pedagogical Motivated Qualitative Study". English for Specific Purposes, 25 (3).

Lim, J. M. H. (2010). "Commenting on Research Results in Applied Linguistics and Education: A Comparative Genre-Based Investigation". Journal of English for Academic Purposes, 9 (4).

Nwogu, K. N. (1997). "The Medical Research Paper: Structure and Functions". English for Specific Purposes, 16(2).

Peacock, M. (2002). "Communicative Moves in the Discussion Section of Research Articles". System, 30 (4).

Peacock, M. (2011). "The Structure of the Methods Section in Research Articles across Eight Disciplines". The Asian ESP Journal, 7 (2).

Posteguillo, S. (1999). "The Schematic Structure of Computer Science Research Articles". English for Specific Purposes, 18 (2).

Samraj, B. (2002). "Introductions in Research Articles: Variation across Disciplines". English for Specific Purposes, 21.

Swales, J. M. (1990). Genre Analysis: English in Academic and Research Settings. Cambridge: Cambridge University Press.

Swales, J. M. (2004). Research Genres: Explorations and Applications. Cambridge: Cambridge University Press.

Swales, J., Feak, C. (2004). Academic Writing for Graduate Students: Essential Tasks and Skills. Ann Arbor: The University of Michigan Press.

Weissberg, R. \& Buker, S. (1990). Writing Up Research: Experimental Research Report Writing for Students of English. Englewood Cliffs. NJ: Prentice-Hall.

Yang, R., Allison, D. (2003). "Research Articles in Applied Linguistics: Moving From Results to Conclusions". English for Specific Purposes, 22 (4). 